\title{
Binucleate blastomeres in preimplantation human embryos in vitro: failure of cytokinesis during early cleavage
}

\author{
K. Hardy, R. M. L. Winston and A. H. Handyside \\ Human Embryology Laboratory, Institute of Obstetrics and Gynaecology, Royal Postgraduate \\ Medical School, Hammersmith Hospital, Du Cane Road, London W12 ONN, UK
}

\begin{abstract}
The nuclei of disaggregated blastomeres from two hundred preimplantation human embryos were examined between days 2 and 4 after insemination in vitro by vital labelling with a polynucleotide-specific fluorochrome. Although the majority of blastomeres had a single nucleus, binucleate blastomeres containing two nuclei of equal size were common and other blastomeres had fragmented nuclei or were anucleate. Seventeen per cent of normally fertilized embryos at the two- to four-cell stage had at least one binucleate blastomere, and this increased to $65 \%$ at the nine- to 16 -cell stage when individual embryos had between one and six binucleate blastomeres. The proportion of binucleate blastomeres in normally fertilized embryos increased from 5 to $10 \%$ over this period, whereas in abnormally fertilized, polyspermic or parthenogenetic, embryos the proportion was significantly higher during early cleavage stages but decreased at the nine- to 16-cell stage when the majority of these embryos arrest ( 25 and $6 \%$, respectively). The incidence of anucleate blastomeres in normally fertilized embryos was also high, especially in those of poor morphology. In contrast, blastomeres with fragmented nuclei were relatively uncommon and the incidence was variable among classes and stages of development. Estimates of the volume of binucleate blastomeres based on measurement of their diameters and comparison with mononucleate blastomeres at various cleavage stages indicated that these blastomeres arise from a failure of cytokinesis between the second and fourth cleavage divisions. On this basis, assignment of binucleate blastomeres to particular cleavage stages in normally fertilized day 4 embryos suggests that at least some of these blastomeres arising during early cleavage persist without further cell division for up to $48 \mathrm{~h}$. At the cellular level, therefore, blastomeres with either binucleate or abnormal nuclei contribute to cleavage stage arrest in vitro.
\end{abstract}

\section{Introduction}

In humans, after in vitro fertilization (IVF), normally fertilized embryos develop to the blastocyst stage in vitro by day 5 or 6 after insemination and by day 7 have about 125 cells, twothirds of which form the outer trophectoderm and one-third the inner cell mass (Hardy et al., 1989a). However, only about half reach the blastocyst stage, while the other half remain arrested predominantly at eight-cell and earlier cleavage stages (Hardy et al., 1989a, b). Even after transfer to the uterus on day 2 or 3 , only $15-30 \%$ of embryos implant and establish pregnancies (ILA report, 1991; Hardy, 1993).

The reasons why so many human embryos undergo cleavage arrest in vitro or fail to develop in vivo are not fully understood. A high incidence of gross genetic defects is likely to be responsible for some of the losses (Plachot et al., 1987). In addition, the simple culture media used routinely for IVF are based on those that have been used successfully in other animal species, particularly mice, and may not be optimal or sufficient for development beyond early stages in vitro. However, a feature of the preimplantation human embryo in vitro is the prevalence of

Received 22 September 1992 morphological abnormalities, including uneven cleavage, cytoplasmic fragmentation and degenerate cells. In particular, various nuclear abnormalities have been reported, including pseudonuclei (Tesarik et al., 1987) and either fragmented, swollen and 'flocculent' nuclei, or total absence of a nucleus (Hardy et al., 1989a). In addition, blastomeres with two or more nuclei have been observed in embryos fertilized both in vivo and in vitro (Hertig et al., 1954; Sathananthan et al., 1982; Lopata et al., 1983; Trounson and Sathananthan, 1984; Plachot et al., 1986; Braude et al., 1990; Winston et al., 1991) and tetraploid and polyploid nuclei have been detected by microfluorimetry and in situ hybridization at cleavage and blastocyst stages (Angell et al., 1987; West et al., 1988; Griffin et al., 1991).

Whatever their respective causes, many of these morphological and nuclear abnormalities clearly contribute to failure of early human development. Binucleate, multinucleate and polyploid blastomeres, however, may be induced by culture in vitro, or, alternatively, represent stages in the formation of polyploid trophoblast cells or multinucleate syncytiotrophoblast (West et al., 1989). During early mouse development, binucleate cells occur in the outer cells of morulae (Soltynska et al., 1985) and in trophoblast cells of the ectoplacental cone (llgren, 1981), both of which form trophoblast giant cells which later become 
progressively more polyploid through a process of endoreduplication in which repeated DNA replication occurs in the absence of cell division.

To contribute additional information, particularly in relation to binucleate blastomeres, we have examined the nuclei of disaggregated blastomeres from normally and abnormally fertilized cleavage stage human embryos, by vital labelling with a DNA-specific fluorochrome, between days 2 and 4 over the period of cleavage arrest in vitro. On day 4 , the diameter of each blastomere was measured to calculate the cytoplasmic volume. Since cleavage divisions successively subdivide the cytoplasm of the zygote and there is no cellular growth, blastomeres become proportionately smaller at later stages. Thus, by reference to the volume of blastomeres from normal embryos that had uniformly and evenly completed particular cleavage divisions, it has been possible to determine how many divisions a blastomere has undergone.

We conclude that binucleate cells are formed by a failure of cytokinesis in the second, third or fourth cleavage divisions, with a peak at the third division, and that the persistence of some binucleate blastomeres for one or two days after their initial formation suggests that they may have undergone cleavage arrest. However, the causes of this are unknown.

\section{Materials and Methods}

\section{Human preimplantation embryos}

The work reported here has been approved by the Human Fertilization and Embryology Authority for Human In-Vitro Fertilization and the Research Ethics committee of the Royal Postgraduate Medical School. Surplus human embryos were obtained with permission from patients undergoing in vitro fertilization (IVF), using a method of superovulation described by Rutherford et al. (1988). After pituitary-gonadal suppression with an LHRH agonist (Buserelin, Hoechst, Hounslow), patients were superovulated with human menopausal gonadotrophin (hMG; Pergonal, Serono, Welwyn Garden City). Human chorionic gonadotrophin (hCG, Pregnyl, Organon, Cambridge), $10000 \mathrm{iu}$ was given $34 \mathrm{~h}$ before egg collection.

Oocytes were collected, preincubated, inseminated (day 0) and checked for pronuclei the following day, as described by Hillier et al. (1984). Embryos were cultured in $1 \mathrm{ml}$ of Earle's balanced salt solution (Gibco, Paisley) supplemented with $25 \mathrm{mmol}$ sodium bicarbonate $\mathrm{l}^{-1}(\mathrm{BDH}$, Lutterworth) and $0.47 \mathrm{mmol}$ pyruvic acid $1^{-1}$ (Sigma, Poole), containing $10 \%$ heat-inactivated maternal serum under a gas phase of $5 \% \mathrm{CO}_{2^{\prime}}$ $5 \% \mathrm{O}_{2}$ and $90 \% \mathrm{~N}_{2}$. On day 2, each fertilized embryo was examined and up to three were selected on the basis of their morphology for embryo transfer on day 2 or 3 . After confirming the patients' consent, the surplus embryos were allowed to develop in vitro in the original medium.

\section{Classification and grading}

Oocytes and embryos were classified initially according to the number of pronuclei visible on day 1 ( $16 \mathrm{~h}$ after insemination) as follows: (i) fertilized embryos (with two pronuclei); (ii) polyspermic embryos (with three or more pronuclei); and (iii) unfertilized oocytes (with one or no pronucleus). Later on day 2, embryos were graded according to evenness of blastomeres, fragmentation and presence of cellular debris from perfectly symmetrical embryos with no fragmentation (grade I) to embryos having one intact blastomere with gross fragmentation (grade IV) or being totally degenerate (grade V). In addition, unfertilized oocytes that cleaved were reclassified as parthenogenetic embryos.

\section{Disaggregation of embryos}

Embryos on days 2, 3 and 4 had their zonae pellucidae removed using acid Tyrodes' solution (Nicolson et al, 1975), $\mathrm{pH} 2.4$, and were washed in Medium M2 supplemented with $4 \mathrm{mg}$ BSA ml $\mathrm{m}^{-1}$ (Crystalline, ICN Biochemicals, High Wycombe) (Quinn et al., 1982). They were disaggregated by gentle pipetting with a flame polished pipette with an internal diameter just smaller than the embryo. With day 4 embryos that were starting to compact, embryos were incubated for $15 \mathrm{~min}$ in Hanks' balanced salt solution without calcium and magnesium (Imperial Laboratories, Andover) supplemented with $6 \mathrm{mg}$ BSA $\mathrm{ml}^{-1}$. Preincubation under calcium- and magnesium-free conditions causes decompaction, facilitating easy disaggregation.

\section{Vital labelling of nuclei}

The nuclei were vitally labelled with the polynucleotidespecific fluorochrome Hoechst 33342 , by a modification of the method of Critser and First (1986). Isolated blastomeres were incubated in M2 plus BSA containing $5 \mu \mathrm{g}$ Hoechst $33342 \mathrm{ml}^{-1}$ (Sigma) for a minimum of $5 \mathrm{~min}$. All the blastomeres from a single embryo were then mounted in a group in $\mathrm{M} 2$ plus BSA in a chamber constructed from a coverslip raised $1 \mathrm{~mm}$ from the surface of a microscope slide with small amounts of Blu-Tack (Bostik, Leicester). Labelled nuclei were examined by fluorescence microscopy with epifluorescent UV illumination using the appropriate filters (A2: Leica UK, Milton Keynes). The number of blastomeres with (i) a single normal sized nucleus (mononucleate); (ii) two (binucleate) or more (multinucleate) equally sized nuclei; (iii) two or more nuclei of various sizes (mainly fragmenting) or (iv) no nucleus (anucleate) were recorded. Groups of blastomeres from each embryo were viewed with $\mathrm{a} \times 20$ objective and photographed with an Olympus OM2 camera and Ilford HP5 film, both under fluorescence and under Hoffman contrast optics. This method allowed mononucleate and binucleate blastomeres to be identified to correlate cell size with the number of nuclei. Negatives showing labelled nuclei were mounted as slides and viewed with a Wotan Diastar 320 slide viewer, which enlarges the image, and enabled the accurate measurement of the diameter of the nuclei.

\section{Staging of blastomeres}

During cleavage, blastomeres become progressively smaller, as there is no cellular growth. Embryos at intermediate cleavage stages consist of a mixture of blastomeres from two consecutive cleavage stages. For example, a six-cell embryo will consist of 
Table 1. Number of cells in cleavage stage human embryos between days 2 and 4 after insemination

\begin{tabular}{lcccc}
\hline $\begin{array}{l}\text { Day } \\
\text { (h after insemination) }\end{array}$ & $\begin{array}{c}\text { Number of } \\
\text { pronuclei }\end{array}$ & Morphology & $\begin{array}{c}\text { Number of } \\
\text { embryos }\end{array}$ & $\begin{array}{c}\text { Mean number of cells } \\
\text { (range) }\end{array}$ \\
\hline 2 & 2 & Good & 13 & $4.0 \pm 0.3(2-7)$ \\
$(46-50)$ & $>2$ & Poor & 18 & $4.3 \pm 0.2(3-6)$ \\
& $<2$ & All & 4 & $6.0 \pm 0.9(4-8)$ \\
3 & 2 & All & 1 & 5.0 \\
$(65-76)$ & $>2$ & Good & 51 & $6.9 \pm 0.3(2-15)$ \\
& $<2$ & Poor & 20 & $6.9 \pm 0.5(3-11)$ \\
4 & 2 & All & 13 & $8.2 \pm 0.7(4-13)$ \\
$(90-97)$ & & Good & 7 & $5.1 \pm 1.0(2-8)$ \\
& $>2$ & Poor & 10 & $12.1 \pm 0.7(5-23)$ \\
& $<2$ & All & 6 & $10.2 \pm 0.7(8-16)$ \\
& & All & 2 & $10.8 \pm 1.3(6-14)$ \\
& & & & $12.0 \pm 1.0(11-13)$ \\
\hline
\end{tabular}

${ }^{a}$ 'Good embryos' are those that are scored as grades 1 and 2 on day 2; 'poor' embryos are those that are scored lower than grade 2.

two larger 'four-cell' blastomeres which still have to divide, and four smaller 'eight-cell' blastomeres. The embryonic stage which individual blastomeres within an embryo had attained was calculated as follows. The expected volume of two-, four-, eight- and 16-cell blastomeres was ascertained by photographing intact and disaggregated grade I embryos with even blastomeres and no fragments at these stages and the diameter of the blastomeres were measured as described above. The range and mean of volumes of two-, four-, eight- and 16-cell blastomeres were then calculated. Binucleate and mononucleate blastomeres identified as described in the previous section could be similarly measured and, on the basis of whether their volumes fell within the range of volumes of reference blastomeres at a particular cleavage stage, assigned to that stage. A minority of blastomeres that fell outside these ranges were assigned on the basis of which mean reference volume they were closest to.

\section{Statistical analysis}

The differences between distributions of numbers and sizes of blastomeres were analysed using the Wilcoxon Rank-Sum (Mann-Whitney) test.

\section{Results}

\section{Cell number and cleavage rate}

Two hundred surplus embryos from 37 patients $(5.4 \pm 0.5$ per patient, range 1-16) were disaggregated into individual blastomeres, where possible, or small groups of blastomeres. Nineteen embryos that were so fragmented that it was impossible to determine cell number accurately and one embryo which was fertilized a day late were excluded from analysis.

For normally fertilized embryos between days 2 and 4 , numbers of blastomeres ranged between 2 and 7 on day 2 to between 5 and 23 on day 4 (Table 1 ). Thus, blastomeres from all stages between the two- and 32-cell stages, resulting from the first to the fifth cleavage divisions, were represented. Cleavage rates in normally fertilized embryos of different morphological grades were similar. Polyspermic embryos on days 2 and 3 appeared to have more blastomeres possibly resulting from some embryos dividing into three blastomeres at the first cleavage division because of the formation of a tripolar spindle (Kola et al., 1987; Plachot et al., 1989).

\section{Analysis of blastomere nuclei}

Although the majority of blastomeres had single nuclei, binucleate blastomeres were common (Figs $1 \mathrm{a}$ and $2 \mathrm{a}$ ), as were anucleate blastomeres (Fig. 2c). A minority of blastomeres had abnormal, multiple nuclei (Figs $2 b, c$ and d), which varied in morphology. Some of these blastomeres had three unevenly sized nuclei which either had a similar labelling intensity to binucleate blastomeres (Fig. 2b) or were swollen, with less intense 'flocculent' labelling (Fig. 2c). Finally, there were blastomeres in which the nuclei were clearly fragmenting (Fig. 2d).

The nuclei in binucleate blastomeres were of the same size as those in mononucleate cells from the same embryo. In nine day-4 embryos, the diameters of the nuclei were $16.7 \pm 0.4 \mu \mathrm{m}$ $(n=39)$ and $16.6 \pm 0.3 \mu \mathrm{m}(n=67)$ in binucleate and mononucleate blastomeres, respectively. Multinucleate blastomeres with more than two nuclei of equal size were rarely observed.

The incidence of binucleate blastomeres was similar in embryos of good and poor morphology (Table 2). The only major difference between normally fertilized embryos of different grades was a significantly higher proportion of anucleate blastomeres in those classified as having poor morphology. The proportion of blastomeres with single nuclei declined between the two- to four-cell stages and later cleavage stages indicating a continued increase in the numbers of binucleate blastomeres and those with nuclear abnormalities (Fig. 3). In contrast, abnormally fertilized embryos had a considerably lower proportion of blastomeres with single nuclei than did normally fertilized embryos at early cleavage stages, mainly as a result of large 

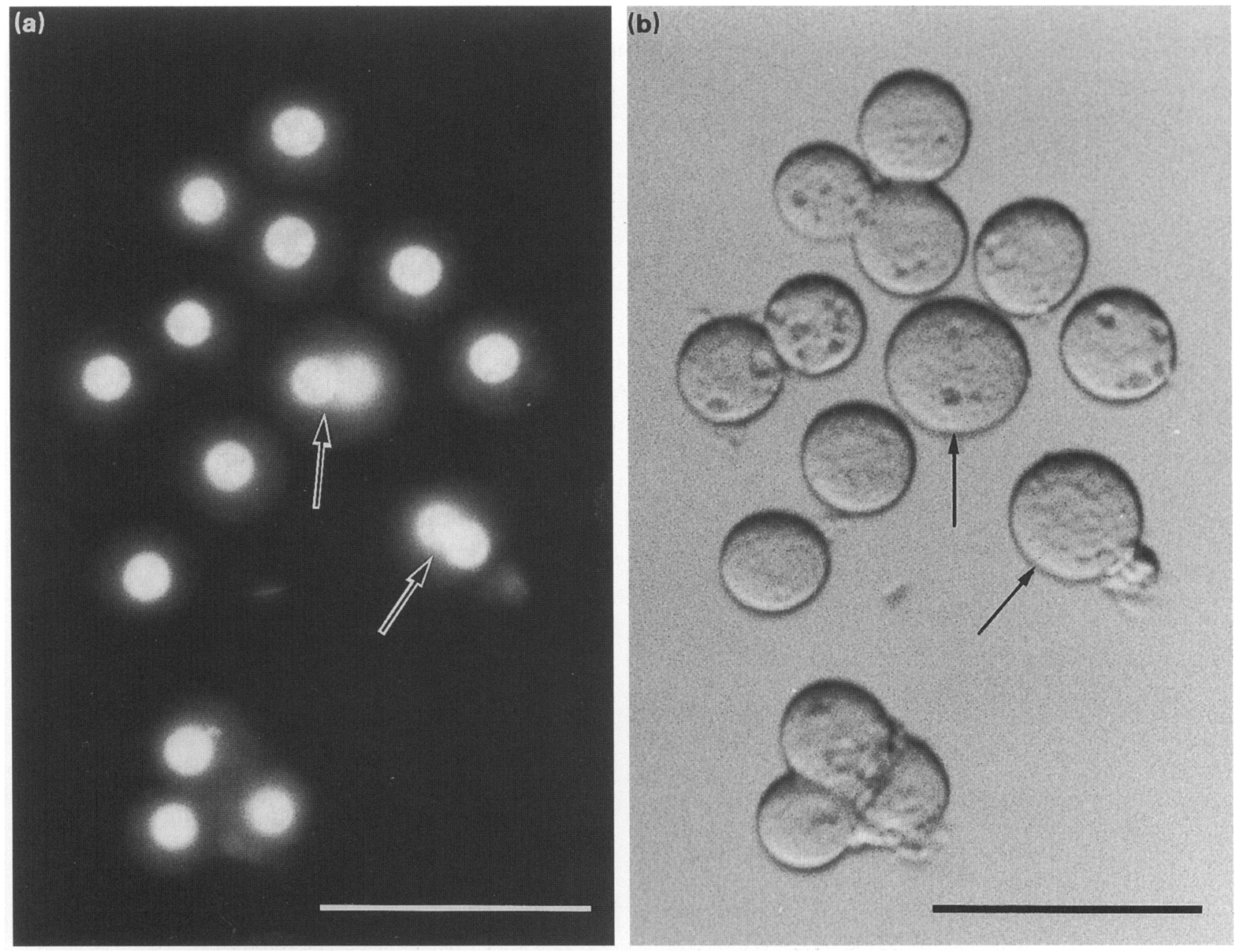

Fig. 1. (a) Fluorescence and (b) Hoffman contrast micrographs of a disaggregated normally fertilized 14-cell human embryo cultured in vitro, of good morphology (grade 1.5), on day 4 after insemination. The nuclei have been labelled with Hoechst 33342 . Binucleate blastomeres (arrows) are approximately twice the volume of blastomeres with one nucleus. (Bar $=100 \mu \mathrm{m}$ )

numbers of binucleate blastomeres and those with fragmenting nuclei, but this proportion increased as cleavage progressed.

Seventeen per cent of embryos had one or more binucleate cells at the two- to four-cell stage and this increased to 65 per cent at the nine- to 16-cell transition (Fig. 4a). The numbers of binucleate blastomeres in each embryo was variable; four-cell embryos never had more than a single binucleate blastomere, whereas embryos at later stages could have two, three or more. The maximum number was six in an eight-cell embryo on day 4 (Fig. 2a). In parallel with the overall increased proportion of anucleate blastomeres in embryos graded as having poor morphology, their distribution was also more widespread in these embryos compared with those of good morphology (Fig. 4b). The percentage of embryos with blastomeres with fragmented nuclei increased but remained low at later cleavage divisions (Fig. 4c).

Fewer abnormally fertilized embryos were analysed, but the pattern of distribution of the blastomeres of different types was similar (Table 3). The only exception was that about twice the number of polyspermic embryos at the five- to eight-cell stage had one or more binucleate blastomeres.

\section{Staging of blastomeres}

Binucleate and mononucleate blastomeres were identified in fifteen disaggregated day 4 embryos that were normally fertilized (mean cell number $12.00 \pm 1.17$, range 6-23 blastomeres) (Table 4). The volumes of a total of 158 blastomeres were measured of which 34 were binucleate and 124 were mononucleate. A further 14 blastomeres were not included: nine were lysed, three had fragmented nuclei and two were anucleate. The mean volume of binucleate blastomeres $\left(8.68 \times 10^{4} \pm\right.$ $6.3 \times 10^{3} \mu^{3}$ ) was significantly greater than the mean volume of mononucleate blastomeres $\left(3.79 \times 10^{4} \pm 2.1 \times 10^{3} \mu^{3}\right)$ $(P=0.0001)$. The majority $(89 \%)$ of blastomeres were assigned to cleavage stages according to which reference range of volumes they matched (Table 4). Eighteen out of 158 blastomeres ( $11 \%$ ) were not within these ranges and therefore were assigned on the basis of which mean reference volume for a particular cleavage stage they were closest to. Although the majority of mononucleate blastomeres $(69 \%)$ were at the 16-cell stage and a further $10 \%$ had reached the 32 -cell stage, the majority of binucleate blastomeres $(65 \%)$ were only at the equivalent of the eight-cell stage with only $15 \%$ reaching the 16-cell stage (Fig. 5). 

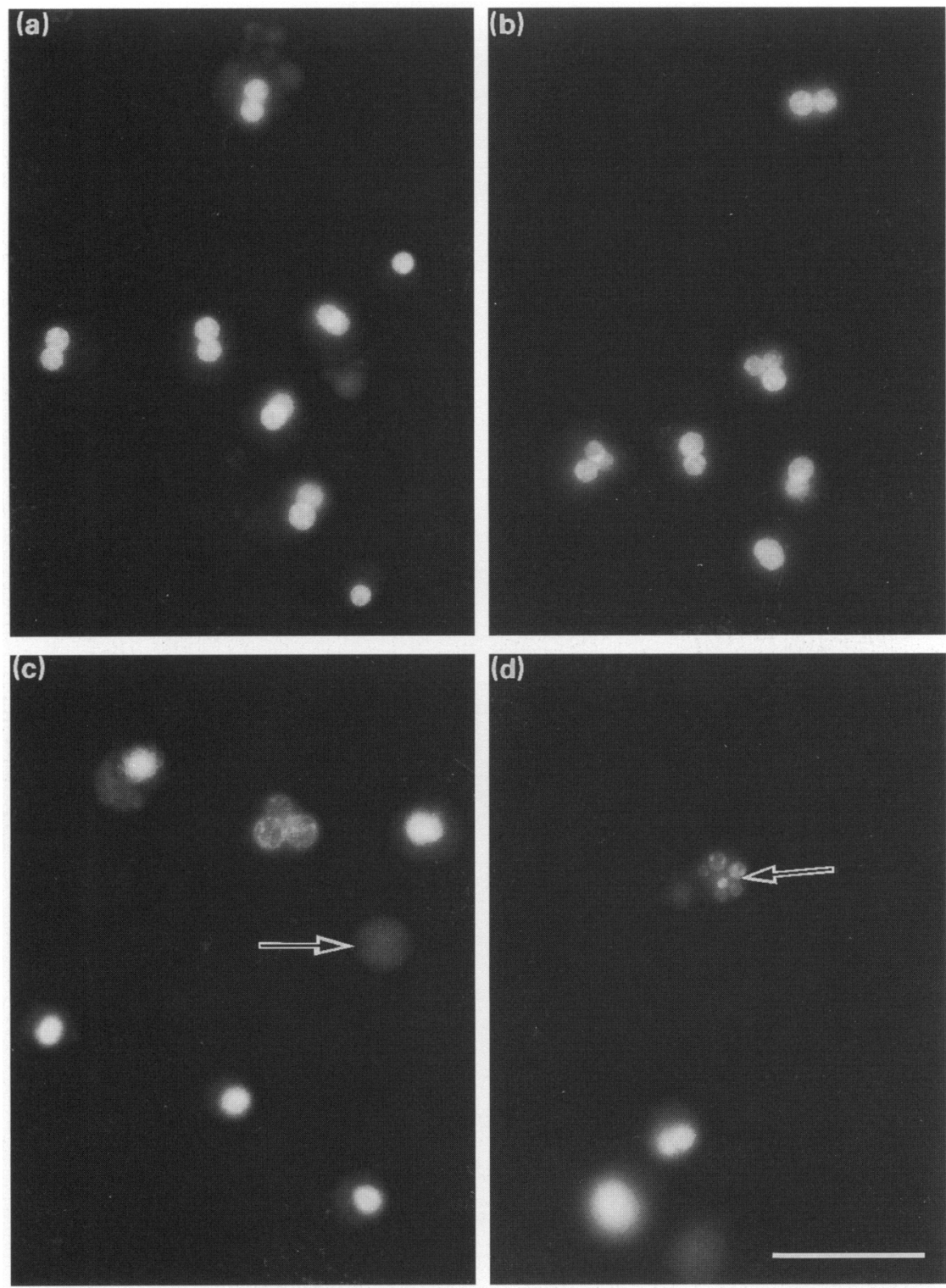

Fig. 2. Fluorescence micrographs of nuclei of disaggregated human embryos cultured in vitro labelled with Hoechst 33342. (a) Normally fertilized grade 2 eight-cell embryo, on day 4 after insemination, showing six binucleate blastomeres. (b) Parthenogenetic grade 3 eight-cell embryo, on day 3 after insemination, showing two binucleate blastomeres and two blastomeres with three nuclei. (c) Partial spread of a normally fertilized grade 2.5 ten-cell embryo, on day 4 after insemination, clearly showing one blastomere with three swollen, flocculent nuclei. Note the anucleate cell (arrow). (d) Partial spread of a normally fertilized grade 2 seven-cell embryo, on day 3 after insemination showing a blastomere containing multiple small, pale labelled nuclear fragments (arrow). (Bar $=100 \mu \mathrm{m})$

The difference in cleavage stage between the binucleate and mononucleate blastomeres is clearly shown (Fig. 1). All twelve mononucleate blastomeres are at the 16-cell stage, whereas the two binucleate blastomeres are double the volume and are still at the eight-cell stage.

\section{Discussion}

Analysis of the nuclei of disaggregated blastomeres from normally and abnormally fertilized human cleavage stage embryos between days 2 and 4 revealed a high incidence of binucleate and anucleate blastomeres and other nuclear abnormalities (mainly fragmentation) with a widespread distribution between embryos. Anucleate blastomeres and those with fragmenting nuclei or other abnormalities clearly lack the potential for further development and are likely, therefore, to contribute to the process of cleavage arrest in vitro and the low pregnancy success rate in vivo after transfer. However, the combined incidence of these anomalies in normally fertilized embryos, even in those of poor morphology, affected a maximum of $16 \%$ of cells at the nine- to 16-cell stage. Embryos lacking one or two blastomeres at about 
Table 2. The percentage of binucleate and anucleate blastomeres and blastomeres with fragmented nuclei in normally fertilized human preimplantation embryos

\begin{tabular}{|c|c|c|c|c|c|c|c|}
\hline \multirow[b]{2}{*}{ Morphology ${ }^{a}$} & \multirow[b]{2}{*}{$\begin{array}{l}\text { Stage } \\
\text { (cell) }\end{array}$} & \multirow[b]{2}{*}{$\begin{array}{l}\text { Number of } \\
\text { embryos }\end{array}$} & \multicolumn{5}{|c|}{ Number of blastomeres } \\
\hline & & & Total & $\begin{array}{c}\text { Binucleate } \\
(\%)^{b}\end{array}$ & $\begin{array}{c}\text { Anucleate } \\
(\%)^{6}\end{array}$ & $\begin{array}{c}\text { Fragmented } \\
(\%)^{\mathrm{b}}\end{array}$ & $\begin{array}{l}\text { Total binucleate or } \\
\text { abnormal }(\%)^{\mathrm{b}}\end{array}$ \\
\hline \multirow[t]{4}{*}{ Good } & $2-4$ & 19 & 71 & $3(4)$ & $2(3)$ & $1(1)$ & $6(8)$ \\
\hline & $5-8$ & 47 & 331 & $27 \quad(8)$ & 18 & $11(3)$ & $56(17)$ \\
\hline & $9-16$ & 29 & 345 & $38(11)$ & 17 (5) & $10(3)$ & $65(19)$ \\
\hline & $>16$ & 4 & 79 & $7(9)$ & $5 \quad(6)$ & $1(1)$ & $13(16)$ \\
\hline \multirow[t]{3}{*}{ Poor } & $2-4$ & 16 & 59 & $3(5)$ & $7(12)$ & 0 & $10(17)$ \\
\hline & $5-8$ & 21 & 143 & $8(6)$ & $22(15)$ & $2(1)$ & $32(23)$ \\
\hline & $9-16$ & 11 & 117 & $16(14)$ & $13(11)$ & $3(3)$ & $32(27)$ \\
\hline
\end{tabular}

${ }^{a}$ 'Good embryos' are those that are scored as grades 1 and 2 on day 2; 'poor' embryos are those that are scored lower than grade 2.

o\% of total number of cells.

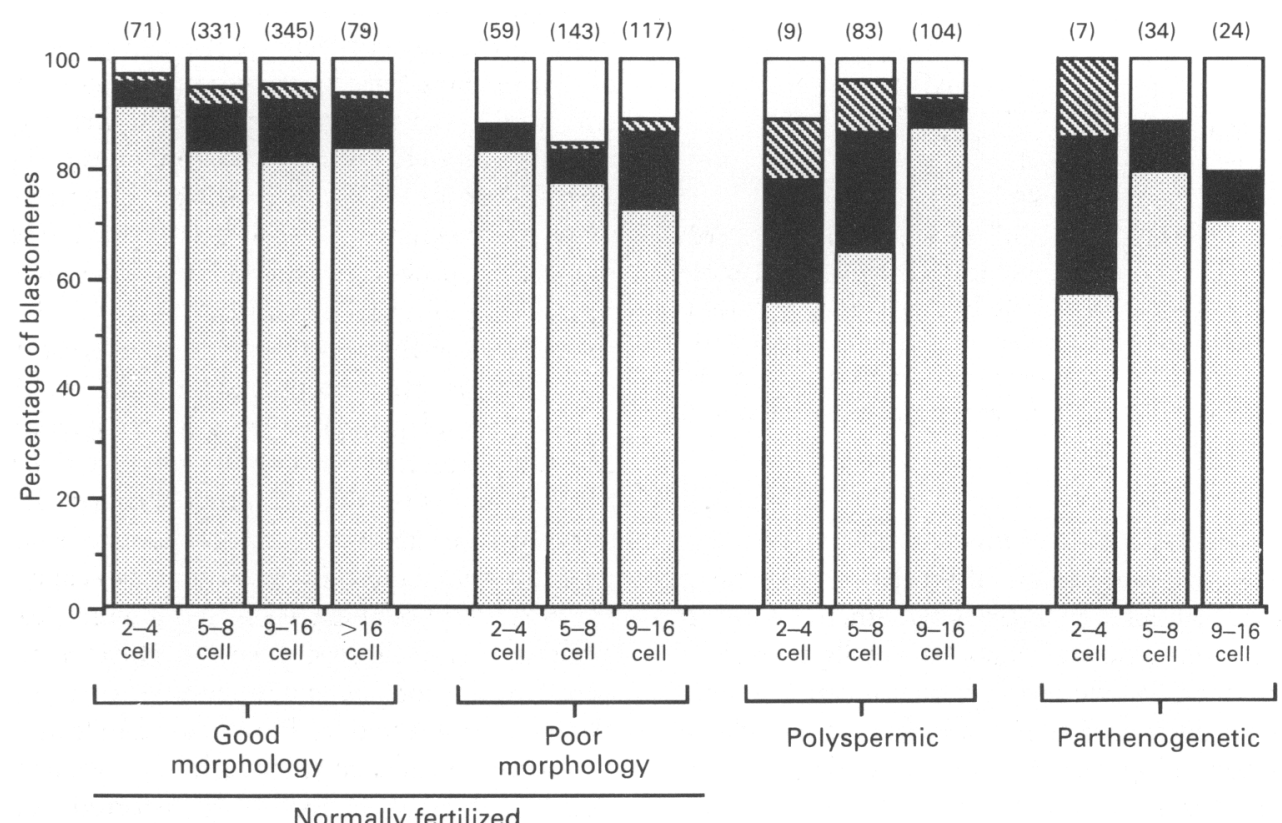

Fig. 3. Percentage of blastomeres in all preimplantation human embryos cultured in vitro, either normally fertilized of good or poor morphology, or abnormally fertilized, which have one nucleus per blastomere (圈); two nuclei per blastomere (binucleate) ( $\boldsymbol{G}$ ); more than two nuclei per blastomere or nuclei of varying sizes $(\$)$ and no nuclei per blastomere (anucleate) $(\square)$. Numbers in parentheses indicate the total number of blastomeres examined.

the eight-cell stage, either after cryopreservation or embryo biopsy, can give rise to pregnancies (Trounson and Mohr, 1983; Handyside et al., 1990), as can embryos known to have multinucleated blastomeres (on the basis of light microscope observations) at the time of transfer (Mohr et al., 1983). Nevertheless, these anomalies are likely to contribute to reduced viability and may reflect other disturbances of development.

Binucleate blastomeres were common. The significance of cells with two apparently normal nuclei of equal size is not clear. Various mechanisms have been described for the formation of binucleate and multinucleate cells, including cell fusion, nuclear amitotic splitting and acytokinesis. Cell fusion is typical of the formation of osteoclasts and striated muscle, and may also be involved in the formation of syncytiotrophoblast. Although the possibility that cell fusion is involved cannot be excluded, it is considered unlikely. In mice, electrophoretic separation of the dimeric enzyme marker glucose phosphate isomerase (GPI) in decidual giant and multinucleated cells from a mouse chimaeric for two electrophoretic variants failed to show an intermediate band indicative of heterokaryon formation between two or more cells of different GPI variants, indicating that cell fusion was not the mode of formation of 

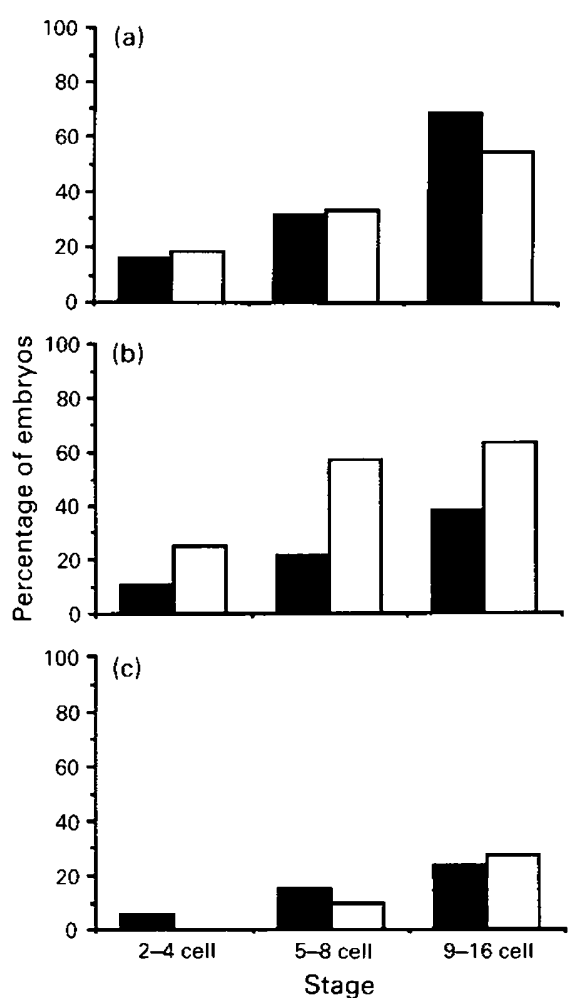

Fig. 4. Percentage of normally fertilized human embryos of ( $\square$ ) good morphology and ( $\square$ ) poor morphology with (a) one or more binucleate, (b) anucleate or (c) multinucleate blastomeres at advancing preimplantation stages in vitro. Nineteen, 47 and 29 embryos of good morphology and 16,21 and 11 embryos of poor morphology at the two- to four-cell, five- to eight-cell and nine- to sixteen-cell stages, respectively, were examined.

binucleate cells (Ansell et al., 1974). However, this approach is not possible with human embryos. An alternative would be to use time lapse cinematography to examine whether cell fusion is involved with the formation of binucleate cells in human preimplantation embryos. In cultured hepatocytes, such a technique was used successfully to demonstrate that mononucleate cells proceed through telophase, but fail to undergo cytoplasmic cleavage, producing cells with two nuclei (Sattler et al., 1988).

Nuclear amitotic splitting involves division of the nucleus with no chromosome replication, and has been observed in liver parenchyma cells as constricted and haploid nuclei (reviewed by Carriere, 1969). However, the failure to observe any constricted nuclei in all of the 1406 blastomeres examined, coupled with the similarity in size between nuclei from binucleate and mononucleate cells, suggests that this mechanism is not involved.

Our results strongly suggest that binucleate blastomeres in human preimplantation embryos arise through acytokinesis, related to cleavage stage arrest. The volume of binucleate blastomeres was almost always greater than the mononucleate blastomeres in the same embryo indicating that those particular blastomeres are still at earlier cleavage stages. The presence of binucleate blastomeres which are still at the four- and eightcell stages along with mononucleate blastomeres at the 16- and even 32-cell stages within the same embryo shows that these blastomeres persist for at least $48 \mathrm{~h}$ and suggests that they have arrested. Similarly, in mice, binucleate blastomeres were larger (Soltynska et al., 1985; Hillman and Hillman, 1975) indicating that a similar mechanism operates. In addition, binucleate blastomeres are characteristic of both homozygous $t^{w 32} / t^{w 32}$ and $t^{12} / t^{12}$ embryos, the majority of which die at the morula stage (Hillman and Hillman, 1975; Hillman et al., 1970), further implicating binucleate blastomeres in developmental arrest. However, although binucleate blastomeres in both mouse and human cleavage stage embryos may be symptomatic of the underlying cause for arrest, they cannot themselves be entirely responsible since only in rare cases did embryos have a majority of these blastomeres. Furthermore, large cells resembling blastomeres at the 16-cell stage have been observed in the blastocoel of human blastocysts (Hardy, 1993), indicating that development to the blastocyst stage can continue despite the arrest of one or more cells at cleavage stages.

Alternatively, binucleate and multinucleate or polyploid cells may be interrelated (Fig. 6) and it has been suggested that polyploid cells, detected at cleavage and blastocyst stages (Angell et al., 1987; West et al., 1988; Griffin et al., 1991) derived through an intermediate binucleate stage, represent an early stage in the development of the syncytiotrophoblast (West et al., 1989). Binucleate blastomeres have been observed in mouse embryos at the morula stage and it was suggested that these blastomeres were the precursors for mural-trophectoderm giant cells (Soltynska et al., 1985). Giant cells in mice are formed in the mural trophectoderm of the blastocyst at the time of implantation, by a process of endoreduplication involving DNA replication without cytokinesis (Barlow et al., 1972). Giant cells are also formed at the periphery of the ectoplacental cone which is derived from polar trophectoderm. Ilgren (1981) found both binucleate and polyploid cells in ectoplacental cone cultures and suggested that binucleate cells gave rise to polyploid cells by nuclear fusion and endoreduplication. However, it seems unlikely that this is the case in humans since binucleate cells arise predominantly in the early cleavage divisions, before trophectoderm differentiation, and multinucleate cells were very rarely observed. It seems more likely that syncytiotrophoblast arises by fusion of mononucleate cytotrophoblast cells as originally suggested by Boyd and Hamilton (1970).

The peak incidence for binucleation occurred during the third cleavage division in the study reported here. This peak coincides with the onset of embryonic gene expression in humans (Braude et al., 1988; Tesarik, 1987, 1988). In mice, embryos from outbred strains arrest at the two-cell stage in vitro and this phenomenon is known as the 'two-cell block', when embryonic gene expression is initiated in mice (Flach et al., 1982; West and Green, 1983; Bolton et al., 1984). Injection of cytoplasm from nonblocking strains to blocking strains at the two-cell stage allowed a higher proportion of embryos that normally block at the two-cell stage to develop to the blastocyst stage, showing that a cytoplasmic factor is responsible for this arrest (Pratt and Muggleton-Harris, 1988). Furthermore, there is evidence in Drosophila that early cleavage divisions depend on maternally derived transcripts (O'Farrell et al., 1989). It is possible that, in humans, deficiencies in maternal macromolecules, possibly as a result of inadequate oocyte maturation, result in a failure of cytokinesis in some blastomeres during early cleavage before embryonic transcription takes over. Potential candidate molecules involved in cytokinesis include cytoskeletal components 
Table 3. Proportion of abnormally fertilized human embryos having one or more binucleate or anucleate blastomeres or blastomeres with fragmented nuclei

\begin{tabular}{|c|c|c|c|c|c|}
\hline \multirow[b]{2}{*}{$\begin{array}{l}\text { Abnormality of } \\
\text { fertilization }\end{array}$} & \multirow[b]{2}{*}{$\begin{array}{l}\text { Stage } \\
\text { (cell) }\end{array}$} & \multicolumn{4}{|c|}{ Number of embryos } \\
\hline & & $\begin{array}{c}\text { Total } \\
\text { number }\end{array}$ & $\begin{array}{c}\text { With binucleate } \\
\text { blastomeres } \\
(\%)\end{array}$ & $\begin{array}{c}\text { With anucleate } \\
\text { blastomeres } \\
(\%)\end{array}$ & $\begin{array}{l}\text { With blastomeres with } \\
\text { fragmented nuclei } \\
(\%)\end{array}$ \\
\hline \multirow[t]{3}{*}{ Polyspermic } & $2-4$ & 2 & 1 & 1 & 1 \\
\hline & $5-8$ & 12 & $10(83 \%)$ & $3(25 \%)$ & $4(33 \%)$ \\
\hline & $9-16$ & 9 & $5(56 \%)$ & $5(56 \%)$ & $1(11 \%)$ \\
\hline \multirow[t]{3}{*}{ Parthenogenetic } & $2-4$ & 3 & 1 & 0 & 1 \\
\hline & $5-8$ & 5 & $2(40 \%)$ & $3(60 \%)$ & 0 \\
\hline & $9-16$ & 2 & 1 & 2 & 0 \\
\hline
\end{tabular}

Table 4. Volumes of blastomeres from grade I 'reference' human embryos with even blastomeres and no fragments

\begin{tabular}{cccc}
\hline $\begin{array}{l}\text { Stage } \\
\text { (cell) }\end{array}$ & $\begin{array}{c}\text { Number of } \\
\text { blastomeres }\end{array}$ & $\begin{array}{c}\text { Mean blastomere volume } \\
\left(\mu^{3}\right)\end{array}$ & $\begin{array}{c}\text { Range } \\
\left(\mu^{3}\right)\end{array}$ \\
\hline 2 & 5 & $3.17 \times 10^{5} \pm 1.5 \times 10^{4}$ & $2.7 \times 10^{5}-3.6 \times 10^{5}$ \\
4 & 21 & $1.42 \times 10^{5} \pm 6.8 \times 10^{3}$ & $1.2 \times 10^{5}-2.2 \times 10^{5}$ \\
8 & 27 & $7.47 \times 10^{4} \pm 2.1 \times 10^{3}$ & $5.8 \times 10^{4}-1.0 \times 10^{5}$ \\
16 & 14 & $2.97 \times 10^{4} \pm 2.4 \times 10^{3}$ & $2.0 \times 10^{4}-4.5 \times 10^{4}$ \\
$32^{*}$ & - & $1.29 \times 10^{4}$ & \\
\hline
\end{tabular}

*Extrapolated from a least squared fit to the observed volumes of two-, four-, eight-, and 16-cell blastomeres.

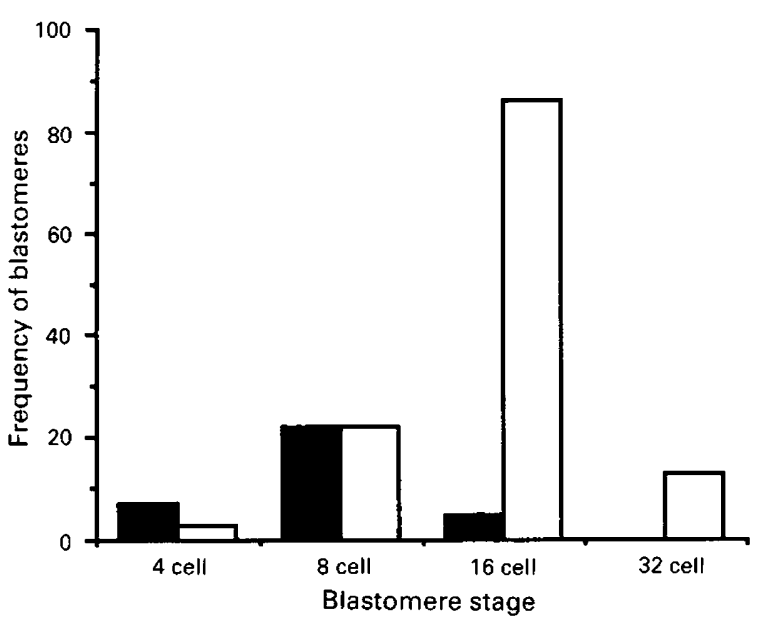

Fig. 5. Embryonic stage of 34 individual binucleate and 124 mononucleate blastomeres in fifteen day 4 normally fertilized human embryos. $(\square)$ mononucleate blastomeres and $(\boldsymbol{\square})$ binucleate blastomeres. One of the mononucleate four-cell blastomeres was in mitosis. Nine lysed, three multinucleate (at the four-, eight- and sixteen-cell stage) and two anucleate (at the 32-cell stage) blastomeres were excluded. crucial for polarization, cell division and compaction (Johnson and Maro, 1986).

Finally, failure of cytokinesis may result from defects at the cell surface level, affecting cell-cell interactions and therefore the shape and behaviour of the cell. After disaggregation of 16cell mouse embryos and further culture, binucleate blastomeres were observed, the majority of which failed to divide (Sherman and Atienza-Samols, 1979). Culturing fibroblasts or certain epithelial cells under conditions that inhibit cell spreading causes an inhibition of cytokinesis and the formation of binucleate cells. When reattachment to the substrate is then allowed, the cells extrude their extra nuclei and become mononucleated (reviewed by Ben-Ze'ev, 1985). It is possible that certain blastomeres in embryos growing in vitro fail to form the necessary interactions with neighbouring blastomeres, resulting in binucleation. Further evidence, in mouse embryos, for the importance of cell interactions in cytokinesis is provided by the observation that a reversible uncoupling of gap junctions between blastomeres occurs during mitosis, an event thought to be crucial in cell division (Goodall and Maro, 1986; Larsen and Wert, 1988).

In conclusion, we suggest that both binucleate blastomeres and blastomeres with nuclear abnormalities result from a process of developmental arrest at the cellular level, which may contribute to the overall low pregnancy rate after transfer 


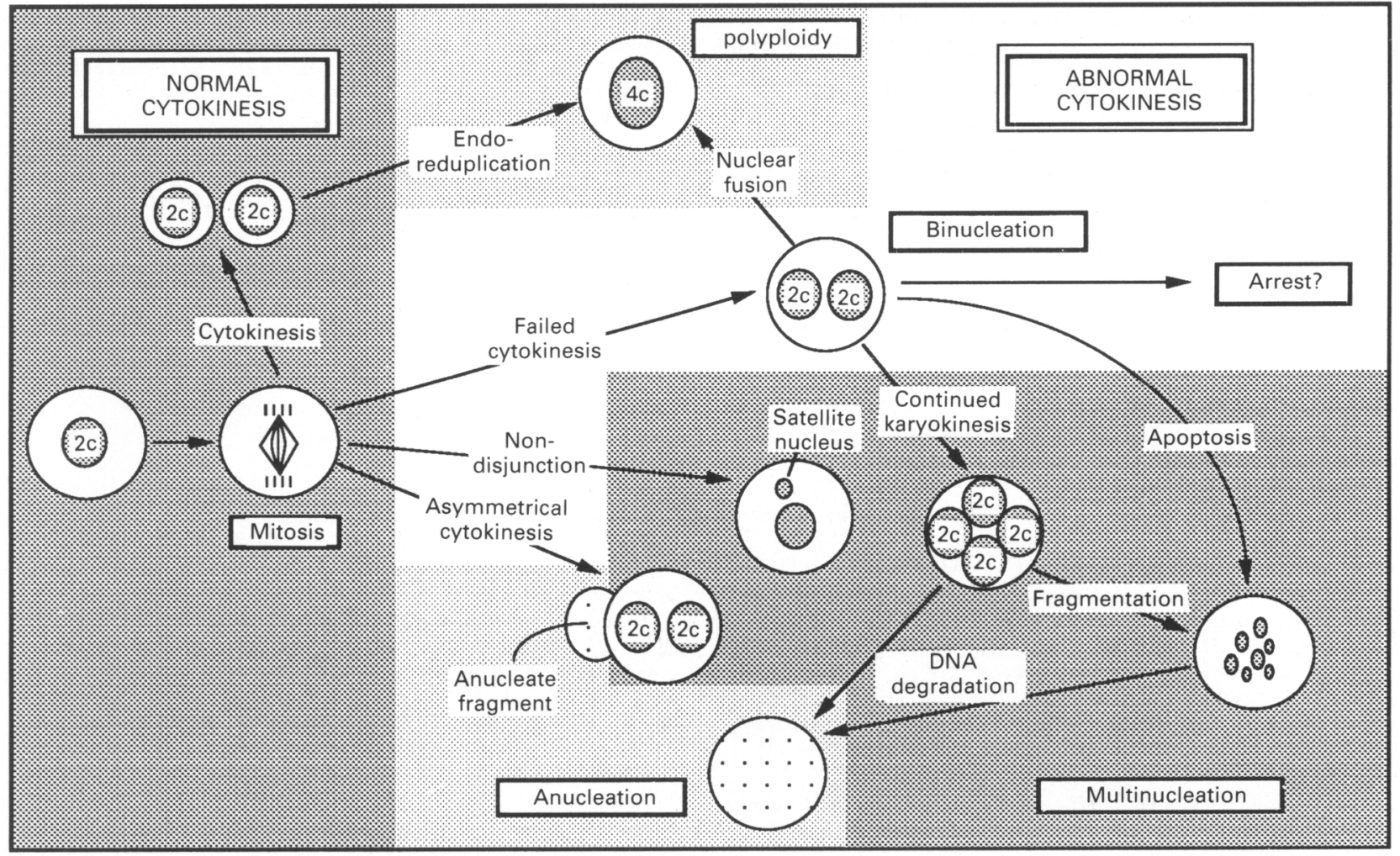

Fig. 6. Hypothetical model demonstrating the possible inter-relationships among binucleate, anucleate, multinucleate and polyploid blastomeres in human preimplantation embryos. 2c: two-cell; $4 \mathrm{c}$ : four-cell.

following IVF. It is not known whether these various abnormalities are caused independently or whether they are interrelated. Various possible interrelationships are suggested (Fig. 6). Under optimal conditions, blastomeres undergo normal cell division and cytokinesis, producing two mononucleate daughter blastomeres. However, if the blastomere is subject to suboptimal conditions, either in the form of less than adequate culture conditions, chromosomal abnormalities, defective cell surface properties or lack of the molecular components that trigger cytoplasmic division, cytokinesis fails and a binucleate cell is formed, which arrests and persists for some time. Multinucleate blastomeres, although rarely observed, could be formed by continued karyokinesis. Fragmenting nuclei may represent a form of cell death similar to apoptosis, and further degradation of these fragments would produce an anucleate cell. An alternative route for the production of anucleate and binucleate blastomeres would be that cytokinesis does occur, but that it is asymmetric, so that one of the daughter blastomeres has two nuclei and the other, smaller one, is anucleate. The polyploid blastomeres seen in cleavage stage embryos (Angell et al., 1987; West et al., 1988) could be produced by endoreduplication of mononucleate blastomeres, fusion of nuclei in binucleate blastomeres, or by the formation of one mitotic spindle during possible division of a binucleate cell, forming two mononucleate daughter blastomeres with polyploid nuclei. Further work needs to be done to follow the fate of binucleate blastomeres in human embryos and to ascertain which of these pathways operates.
The authors are grateful to K. Dawson, IVF laboratory director, and members of her team, for their care and expertise in the collection and establishment of the surplus embryos used in this study.

\section{References}

Angell RR, Sumner AT, West JD, Thatcher SS, Glasier AF and Baird DT (1987) Post-fertilization polyploidy in human preimplantation embryos fertilized invitro Human Reproduction 2 721-727

Ansell JD, Barlow PW and McLaren A (1974) Binucleate and polyploid blastomeres in the decidua of the mouse Journal of Embryology and Experimental Morphology 31 223-227

Barlow P, Owen DAJ and Graham C (1972) DNA synthesis in the preimplantation mouse embryo Journal of Embryology and Experimental Morphology 27 $431-445$

Ben-Ze'ev A (1985) Cell shape, the complex cellular networks, and gene expression Cell and Muscle Motility 6 23-53

Bolton VN, Oades PJ and Johnson MH (1984) The relationship between cleavage, DNA replication and gene expression in the mouse 2-cell embryo Journal of Embryology and Experimental Morphology 79 139-163

Boyd JD and Hamilton WJ (1970) The Human Placenta. W. Heffer and Sons Ltd, Cambridge

Braude P, Bolton V and Moore S (1988) Human gene expression first occurs between the four- and eight-cell stages of preimplantation development Nature 332 459-46I

Braude PR, Pickering SJ, Winston NJ, Artley JK and Johnson MH (1990) The development of the human preimplantation embryo. In From Ovulation to Implantation, pp 251-261 Ed. JLH Evers and MJ Heineman. Elsevier Science Publishers, Amsterdam

Carriere R (1969) The growth of liver parenchymal nuclei and its endocrine regulation International Review of Cytology 25 201-277

Critser ES and First NL (1986) Use of a fluorescent stain for visualization of nuclear material in living oocytes and early embryos Stain Technology 61 1-5 
Flach G, Johnson MH, Braude PR, Taylor RAS and Boiton VN (1982) The transition from maternal to embryonic control in the 2-cell mouse embryo $E M B O$ Journal $1681-686$

Goodall H and Maro B (1986) Major loss of junctional coupling during mitosis in early mouse embryos journal of Cell Biology 102 568-575

Griffin DK, Handyside AH, Penketh RJA, Winston RML and Delhanty JDA (1991) Fluorescent in situ hybridisation to interphase nuclei of human preimplantation embryos with $X$ and $Y$ chromosome specific probes Human Reproduction 6 101-105

Handyside AH, Kontogianni EH, Hardy K and Winston RML (1990) Pregnancies from biopsied human preimplantation embryos sexed by $Y$-specific DNA amplification Nature 344 768-770

Hardy K (1993) Development of human blastocysts in vitro. In Preimplantation Embryo Development pp 184-199 Ed. B Bavister. Springer-Verlag, New York

Hardy K, Handyside AH and Winston RML (1989a) The human blastocyst: cell number, death and allocation during late preimplantation development in vitro Development 107 597-604

Hardy K, Hooper MAK, Handyside AH, Rutherford AJ, Winston RML and Leese HJ (1989b) Non-invasive measurement of glucose and pyruvate uptake by individual human oocytes and preimplantation embryos Human Reproduction 4 188-191

Hertig AT, Rock J, Adams EC and Mulligan WJ (1954) On the preimplantation stages of the human ovum: a description of four normal and four abnormal specimens ranging from the second to the fifth day of development Contributions to Embryology 35 199-220

Hillier SG, Dawson KJ, Afnan M, Margara RA, Ryder TA, Wickings EJ and Winston RML (1984) Embryo culture: quality control in in vitro fertilization. In Proceedings of the Twelfth Study Group of the Royal College of Obstetricians and Gynaecologists, pp 125-140 Ed. W Thompson, DN Joyce and JR Newton. Royal College of Obstetricians and Gynaecologists, London

Hillman N and Hillman R (1975) Ultrastructural studies of $t^{2032} / f^{2032}$ mouse embryos Journal of Embryology and Experimental Morphology 33 685-695

Hillman N, Hillman R and Wileman G (1970) Ultrastructural studies of cleavage stage $t^{12} / t^{12}$ mouse embryos American Journal of Anatomy 128 311-340

ILA (1991) The Sixth Report of the Interim Licensing Authority for Human In vitro Fertilization and Embryology ILA 1991, Clements House, London

Ilgren EB (1981) On the control of the trophoblastic giant-cell transformation in the mouse: homotypic cellular interactions and polyploidy Journal of Embryology and Experimental Morphology 62 183-202

Johnson MH and Maro B (1986) Time and space in the mouse early embryo: a cell biological approach to cell diversification. In Experimental Approaches to Mammalian Embryonic Development, pp 35-65 Ed. J Rossant and RA Pedersen. Cambridge University Press, Cambridge

Kola I, Trounson A, Dawson G and Rogers P (1987) Tripronuclear human oocytes: altered cleavage patterns and subsequent karyotype analysis of embryos Biology of Reproduction 37 395-401

Larsen WJ and Wert SE (1988) Roles of cell junctions in gametogenesis and in early embryonic development Tissue and Cell 20 809-848

Lopata A, Kohlman D and Johnston I (1983) The fine structure of normal and abnormal human embryos developed in culture. In Fertilization of the Human Egg In vitro, pp 189-210 Ed. HM Beier and HR Lindner. Springer-Verlag, Berlin, Heidelberg

Mohr LR, Trounson AO, Leeton JF and Wood C (1983) Evaluation of normal and abnormal human embryo development during procedures in vitro. In Fertilization of the Human Egg In vitro, pp 211-221 Ed. HM Beier and HR Lindner. Springer-Verlag, Berlin, Heidelberg

Nicolson GL, Yanagamachi R and Yanagamachi H (1975) Ultrastructural localisation of lectin-binding sites on the zonae pellucidae and plasma membranes of mammalian eggs Joumal of Cell Biology 66 263-274

O'Farrell PH, Edgar BA, Lakich D and Lehner CF (1989) Directing cell division during development Science 246 635-640
Plachot M, Mandelbaum J, Junca A-M, De Grouchy J, Cohen J, Salat-Baroux J and Da Lage C (1986) Morphologic, cytologic and cytogenetic studies of human embryos obtained by IVF. In In vitro Fertilization. Proceedings of the Twelfth World Congress on Fertility and Sterility (Vol. 2), pp 61-65 Ed. SS Ratnam and ES Teoh. Parthenon Publishing Group, Lancs, UK

Plachot M, De Grouchy J, Junca A-M, Mandelbaum J, Turleau C, Couillin P, Cohen J and Salat-Baroux J (1987) From oocyte to embryo: a model, deduced from in vitro fertilization, for natural selection against chromosome abnormalities Annales de Génétique 30 22-32

Plachot M. Mandelbaum J, Junca A-M, De Grouchy J, Salat-Baroux J and Cohen J (1989) Cytogenetic analysis and developmental capacity of normal and abnormal embryos after IVF Human Reproduction 4 99-103

Pratt HPM and Muggleton-Harris AL (1988) Cycling cytoplasmic factors that promote mitosis in the cultured 2-cell mouse embryo Development 104 $115-120$

Quinn P, Barros C and Whittingham DG (1982) Preservation of hamster oocytes to assay the fertilizing capacity of human spermatozoa Journal of Reproduction and Fertility 66 161-168

Rutherford AJ, Subak-Sharpe R, Dawson K, Margara RA, Franks S and Winston RML (1988) Improvement of in vitro fertilization after treatment with buserelin, an agonist of luteinising hormone releasing hormone British Medical Journal 296 1765-1768

Sathananthan AH, Wood C and Leeton JF (1982) Ultrastructural evaluation of 8-16 cell human embryos cultured in vitro Micron 13 193-203

Sattler CA, Sawada N, Sattler GL and Pitot HC (1988) Electron microscopic and time lapse studies of mitosis in cultured rat hepatocytes Hepatology 8 $1540-1549$

Sherman MI and Atienza-Samols SB (1979) Differentiation of mouse trophoblast does not require cell-cell interaction Experimental Cell Research 123 73-77

Soltynska MS, Balakier H, Witkowska A and Karasiewicz J (1985) Binucleate blastomeres in mouse morulae Roux's Archives of Developmental Biology 194 173-177

Tesarik J (1987) Gene activation in the human embryo developing in vitro. In Future Aspects in Human In vitro Fertilization, pp 251-261 Ed. W Feichtinger and $\mathrm{P}$ Kemeter. Springer-Verlag, Berlin, Heidelberg

Tesarik J (1988) Early morphological signs of embryonic genome expression in human preimplantation development as revealed by quantitative electron microscopy Developmental Biology 128 15-20

Tesarik J, Kopecny V, Plachot M and Mandelbaum J (1987) Ultrastructural and autoradiographic observations on multinucleated blastomeres of human cleaving embryos obtained by in-vitro fertilization Human Reproduction 2 $127-136$

Trounson A and Mohr L (1983) Human pregnancy following cryopreservation, thawing and transfer of an eight-cell embryo Nature 305 707-709

Trounson A and Sathananthan AH (1984) The application of electron microscopy in the evaluation of two- to four-cell human embryos cultured in vitro for embryo transfer journal of in vitro Fertilization and Embryo Transfer 1 153-165

West JD and Green JF (1983) The transition from oocyte-coded to embryocoded glucose phosphate isomerase in the early mouse embryo Joumal of Embryology and Experimental Morphology 78 127-140

West JD, Gosden JR, Angell RR, West KT, Glasier AF, Thatcher SS and Baird DT (1988) Sexing whole human pre-embryos by in-situ hybridization with a Y-chromosome specific DNA probe Human Reproduction 3 1010-1019

West JD, Gosden CM, Gosden JR, West KR, Davidson Z, Davidson C and Nicolaides KH (1989) Sexing the human fetus and identification of polyploid nuclei by DNA-DNA in situ hybridisation in interphase nuclei Molecular Reproduction and Development 1 129-137

Winston NJ, Braude PR, Pickering SI, George MA, Cant A, Currie J and Johnson MH (1991) The incidence of abnormal morphology and nucleocytoplasmic ratios in 2-, 3- and 5-day human pre-embryos Human Reproduction 6 17-24 